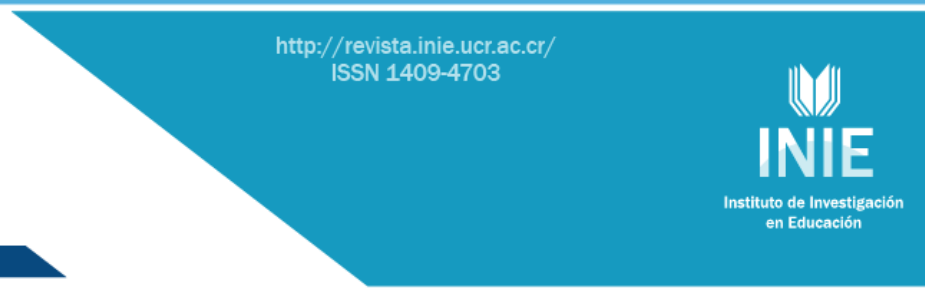

\title{
POSITIVISMO, DIALÉCTICA MATERIALISTA Y FENOMENOLOGÍA: TRES ENFOQUES FILOSÓFICOS DEL MÉTODO CIENTÍFICO Y LA INVESTIGACIÓN EDUCATIVA \\ POSITIVISM, DIALECTIC MATERIALIST AND PHENOMENOLOGY: THREE PHILOSOPHICAL APPROACHES FROM THE SCIENTIFIC METHOD AND THE EDUCATIVE INVESTIGATION
}

\section{Volumen 14, Número 3 \\ Setiembre - Diciembre}

pp. $1-20$

Este número se publicó el 30 de setiembre de 2014

\author{
Alberto Matías González \\ Antonio Hernández Alegría
}

Revista indizada en REDALYC, $\underline{\text { SCIELO }}$

Revista distribuida en las bases de datos:

CATÁLOGO DE LATINDEX, IRESIE, CLASE, DIALNET, DOAJ, E-REVIST@S, SHERPA/ROMEO, QUALIS, MIAR

Revista registrada en los directorios:

ULRICH'S, REDIE, RINACE, OEI, MAESTROTECA, PREAL, $\underline{\text { CLACSO }}$ 


\title{
POSITIVISMO, DIALÉCTICA MATERIALISTA Y FENOMENOLOGÍA: TRES ENFOQUES FILOSÓFICOS DEL MÉTODO CIENTÍFICO Y LA INVESTIGACIÓN EDUCATIVA \\ POSITIVISM, DIALECTIC MATERIALIST AND PHENOMENOLOGY: THREE PHILOSOPHICAL APPROACHES FROM THE SCIENTIFIC METHOD AND THE EDUCATIVE INVESTIGATION
}

\author{
Alberto Matías González \\ Antonio Hernández Alegría ${ }^{2}$
}

\begin{abstract}
Resumen: En el presente ensayo los autores pretenden exponer consideraciones acerca del lugar y la presencia del positivismo, la dialéctica materialista y la fenomenología como enfoques del método científico, al mismo tiempo, identificar su valor para la investigación educativa. No se consideran estas tres orientaciones como las únicas, ni las más importantes, es solo que tienen un espacio considerable en las creencias de los investigadores y en el debate académico y pueden ser puentes para asumir ideas filosóficas novedosas. La reflexión se hace desde una perspectiva que entra a cavilar sobre la realidad latinoamericana y en la que se muestran argumentos básicos de la interacción entre la filosofía y el método científico. El trabajo ha sido desarrollado a partir de la consulta de una extensa bibliografía que incluye tesis de maestría y de opción al grado científico de Doctor y de escuchar las opiniones de varios estudiosos que toman como campo la educación. Desde perspectivas muy heterogéneas, las distintas corrientes del pensamiento social y filosófico de los últimos siglos han estado ligadas a la evolución del proceder científico de producir el conocimiento, por lo que reflexionar sobre ello ofrece la oportunidad de apropiarse de criterios que pueden ser útiles para los científicos. Estar en posesión de buenos argumentos filosóficos para justificar las acciones investigativas impacta de manera positiva la actividad científica.
\end{abstract}

Palabras clave: POSITIVISMO, DIALÉCTICA, MATERIALISMO, FENOMENOLOGÍA, EDUCACIÓN, INVESTIGACIÓN EDUCATIVA.

\begin{abstract}
Through this essay authors intend to expose some considerations related to the place and presence of positivism, materialist dialectic and phenomenology as approaches of the scientific method, and at the same time to identify its value to the educative investigation. These three orientation lines are not considered as the only ones or the most important one. It is just that they have a considerable space in the researcher's believes and in nowadays academic debate and they can be bridges to assume new philosophical ideas. The reflection is made from a perspective that leads to think over the Latin American reality and where basic arguments of the interaction between philosophy and the scientific method are expressed. This work has been carried out from the revision of a wide bibliography that includes Master degree and PhD thesis and listening to different opinions from outstanding people who take education as field of action. From very heterogeneous perspectives the different social and philosophical and social thought tendencies of the last centuries have been linked to the evolution of the scientific way to produce knowledge, that's why to think over it offers an opportunity to grasp the criteria that can be useful for scientists. To have good philosophical arguments to justify the researching actions makes a positive impact on the scientific activity.
\end{abstract}

Key words: POSITIVISM, DIALECTIC, MATERIALIST, PHENOMENOLOGY, EDUCATION, EDUCATIONAL RESEARCH.

\footnotetext{
"Profesor Titular de la Universidad de Sancti Spíritus "José Martí Pérez", Máster en Ciencia, Tecnología y Sociedad, por la Universidad de la Habana y Doctor en Gestión ambiental y desarrollo sostenible, por la Universidad de Girona, España. Imparte en el posgrado Filosofía de la educación. Dirección electrónica: matias@suss.co.cu

2 Profesor Auxiliar e imparte Filosofía en la Universidad Pedagógica de Sancti Spíritus, Capitán Silverio Blanco Núñez. Es Doctor en Filosofía, Imparte en el posgrado Filosofía de la educación. Dirección electrónica: aalegria@ucp.ss.rimed.cu
}

Ensayo recibido: 19 de diciembre, 2013

Enviado para corrección: 29 de abril, 2014

Aprobado: $1^{\circ}$ de setiembre, 2014 


\section{Introducción}

La explicación de los orígenes de la ciencia, el método científico, la investigación y la relación de estos con la filosofía cuenta con muchas versiones que van desde las teorías que argumentan que la ciencia se desgajó de la filosofía, hasta las que de modo contrario afirman que la filosofía nace de saberes y prácticas científicas y técnicas ya establecidas. Pero, independientemente de las divergencias, es evidente que a través de la Historia han coexistido en un trasvase recíproco de creencias.

Una de las regiones del saber donde este trasvase recíproco se manifiesta es en la concepción del método científico y muy, en especial, en las ciencias que estudian la sociedad humana, entre ellas, las Ciencias de la Educación. Aquí, la presencia de enfoques filosóficos alcanza tanto formas muy evidentes como formas más sutiles y encubiertas, que actúan como expresión del tejido social y del rejuego de relaciones de poder en las distintas épocas y contextos sociales.

Los enfoques filosóficos, se quiera o no, penetran la actividad investigativa aunque el investigador no sea consciente de ello, "no se puede prescindir de la filosofía", afirma Mario Bumge (2002, p. 10), pero necesitamos de argumentos pertinentes que expresen una buena filosofía.

En ese sentido, el positivismo, la fenomenología y la dialéctica materialista del marxismo están dentro de las teorías filosóficas que han dejado su huella en la investigación educativa de los últimos 150 años. Cada una de estas perspectivas epistemológicas tuvo unas circunstancias sociales de gestación específicas y fundamentos históricos contextuales propios.

Frente a tal escenario, en el presente ensayo se pretende exponer consideraciones acerca de la presencia de estas tres tradiciones filosóficas en la manera científica de producir el conocimiento y sobre su valor para la investigación educativa, a fin de mostrar argumentos básicos de utilidad para los investigadores.

De hecho, es natural entender que es una elección un poco esquemática, si tenemos en cuenta la influencia que otros paradigmas filosóficos han alcanzado en las últimas décadas, pero, indudablemente, estas ocupan un espacio considerable en la academia y en la investigación social de la región, al mismo tiempo, muchos de sus ideales se entrecruzan con otras formas explicativas actualmente de moda.

Por eso, la reflexión se hace desde un enfoque latinoamericano, al considerar como punto de partida la necesidad de gestar un pensamiento propio, autóctono para la región. 
La América Latina, en los campos del arte, la ciencia y la educación, ha sido escenario de absorción de las modas del pensamiento filosófico europeo, esto -y sin llegar a negar las virtudes de dichas tradiciones- ocurre en detrimento de la formación de una identidad propia.

De igual manera, en las últimas décadas se ha incrementado la investigación en el campo de la educación, lo que es sumamente importante por la función de orientación que tiene la ciencia en la formación de una cultura ciudadana y de los prototipos de mujeres y hombres que requiere la sociedad latinoamericana, pero se necesita de procesos que asuman con claridad de conciencia la filosofía que se maneja. Es más, conocer sobre el origen de los términos y argumentos con que operamos es una forma de construir libertades. Razón por la cual en los conceptos y percepciones que se usan pueden existir manipulaciones sutiles con cargas ideológicas que nada tienen que ver con el mejoramiento social de la región.

Antes de hacer referencia a las corrientes filosóficas y su presencia en lo que históricamente se ha llamado método científico, se hace necesario establecer algunas precisiones al respecto, a fin de introducir el marco conceptual de que se parte.

\section{El método científico}

El método científico, en su interpretación tradicional, es un instrumento que hace posible y le da un sello distintivo a la construcción del conocimiento, como uno de los modos históricos de conocimiento, y aunque es indudable que este tiene una importancia cada vez más creciente en la vida humana y en la relación de esta con el entorno, para los autores no es el único capaz de proporcionar respuestas verdaderas o falsas a las interrogantes que plantea el ser humano.

Martin Heidegger, al destacar la importancia del método científico, señala que "El método no es una pieza de la indumentaria de la ciencia entre otras, sino la instancia fundamental a partir de la cual se determina lo que puede llegar a ser objeto y cómo puede llegar a serlo" (1975, p. 93).

El primer método científico, del que la historia de la ciencia tradicional hace referencia, es el método axiomático de Aristóteles, quien sintetizó el saber filosófico de su tiempo: la ciencia se constituye de un conjunto de axiomas ciertos, descubiertos por intuición, con los cuales se elaboran, a partir de determinadas reglas, todas las pretensiones a la verdad. 
Entendido desde la condición moderna como conjunto de reglas y certezas previas, visión actualmente sometida a críticas por los teóricos del pensamiento complejo, el método científico aparece alrededor del siglo XVI y se relaciona con la labor de Galileo Galilei y de René Descartes.

La conformación inicial del método hipotético deductivo, como se plasma en la mayoría de las investigaciones de los últimos siglos, se refiere a: partir de un cuerpo previo de conocimientos, identificar un problema, exponer hipótesis, buscar evidencias, valorar el o los resultados e integrar las hipótesis contrastadas en principios, leyes y teorías.

Generalmente, se reconoce en la literatura científica y filosófica a Descartes como el símbolo del método científico moderno, porque estableció el conjunto de reglas "supremas" y destacó su significado para producir conocimientos.

Ya en Descartes se presenta con nitidez uno de los puntos débiles del pensamiento moderno: la separación del sujeto y el objeto, una matriz donde el sujeto se autoelimina a sí mismo (Delgado, 2002, p. 40), para lograr supuestamente alcanzar un conocimiento objetivo sobre las propiedades objetivas del universo y, a través de ese saber, se accede a la práctica de elaborar tecnologías para transformar el mundo.

Con la eliminación del sujeto real, la ciencia floreció como saber "exacto" sobre el mundo objetivo, y al no reconocer la subjetividad, el proyecto moderno cayó en la negación del contenido axiológico del conocimiento.

Descartes presupone que es posible partir de ese conjunto de reglas ciertas que se pueden seguir, y con ello arribar a fines cognoscitivos eficaces, para fundar una ciencia de la certidumbre y del dominio del hombre sobre la naturaleza, es decir,

Así, pues, entiendo por método reglas ciertas y fáciles, mediante las cuales el que las observe exactamente no tomará nunca nada falso por verdadero, $y$, no empleando inútilmente ningún esfuerzo de la mente, sino aumentando siempre gradualmente su ciencia, llegará al conocimiento verdadero de todo aquello de que es capaz. (Descartes, 1984, p. 79)

Al referirse a la importancia del método científico, Descartes visualiza uno de los ejes que identifican el mundo moderno: la percepción privilegiada de la figura del sujeto investigador en la transformación del objeto. Esto marcó, con posterioridad, una influencia en las ciencias sociales y en especial en la educación, espacio este donde se llega a 
considerar al alumno a modo de objeto del cambio, sin entrar a considerarlo como sujeto de autotransformación. El siguiente fragnento es evidencia del nuevo rol atribuido al sujeto.

...en lugar de la filosofía especulativa, enseñada en las escuelas, es posible encontrar una práctica, por medio de la cual, conociendo de la fuerza y las acciones del fuego, del agua, del aire, de los astros, de los cielos y de todos los demás cuerpos, que nos rodean, tan distintamente como conocemos los oficios varios de nuestros artesanos, podríamos aprovecharlas del mismo modo, en todos los usos a que sean propias, y de esa suerte hacernos como dueños y poseedores de la naturaleza. (Descartes, 1953, p. 152)

Así desde los orígenes de la modernidad en el siglo XVII se fue construyendo una ideología conocida con la denominación de racionalidad clásica, que difundió una percepción de confianza absoluta en la certeza del conocimiento científico; creencia de certeza que en la actualidad participa de agudas controversias, pues conduce al escenario ideal para que el sujeto social se sienta en posesión segura de la verdad, seguridad que lo hace insensible al error (Morin, Ciurana y Motta, 2002, p. 22) y a negar la diversidad de creencias científicas, e incluso del valor de las no científicas.

Por su lado, el fundamento que ha legitimado el método científico moderno deja un espíritu de excesivo optimismo en cuanto a las potencialidades humanas de "dominar" la naturaleza, espíritu que ha transferido su huella negativa al deterioro actual del medio ambiente.

Esta ideología, nacida en los siglos XVII y XVIII, va a ser posteriormente asumida y legitimada por la filosofía positivista en los siglos XIX y XX y se ha asentado con firmeza en las creencias de los investigadores.

En las últimas décadas nace una comprensión emergente y alternativa a esta consideración clásica racionalista del método científico, que acentúa su preocupación por la duda, la incompletud y la incertidumbre del conocimiento y tiende a romper la confianza tradicional en cuanto a los resultados de la ciencia. Esta comprensión considera que

El método es un discurso, un ensayo prolongado de un camino que se piensa. Es un viaje, un desafío, una travesía, una estrategia que se ensaya para llegar a un final pensado, imaginado y al mismo tiempo insólito, imprevisto y errante. No es el 
discurrir de un pensamiento seguro de sí mismo, es una búsqueda que se inventa y se reconstruye continuamente. (Morin et al., 2002, p. 12)

En la base del cambio de perspectiva está una comprensión de la diversidad y la dialéctica del universo y de los asuntos de la vida en sociedad, así como de los peligros asociados a la acción humana. Se parte de que el método científico no ha sido estático, más bien, es partícipe de una interactividad creciente, en su fundamento teórico e ideológico y en procedimientos técnicos que condicionan su pluralidad y su multidimensionalidad, condición que emana de la diversidad de la acción práctica social. Los hechos no son lineales o estáticos, por el contrario, son multidimensionales y multidireccionales; en ellos inciden fenómenos de diverso orden: económicos, políticos, culturales, emotivos, pasionales etc., que se hallan en una permanente transformación, formando redes interconectadas entre sí.

Para la investigación educativa es crucial entender esta dialéctica que se da en el desempeño didáctico e investigativo del ejercicio profesional. En el discurso educativo actual se introducen conceptos como multiculturalidad, educación permanente, cultura del riesgo, pertinencia, democratización de la enseñanza, educación inclusiva, calidad de la educación, educación digna, etc., que constituyen demandas de la formación científica y ética; visto desde un enfoque más amplio, estamos ante las exigencias de una mayor democratización y humanización de la sociedad del presente.

Todo ello implica rechazar cualquier forma dogmática y de ortodoxia, y propicia un desempeño científico e investigativo que permite asimilar todo lo legítimo aportado a la teoría y la metodología de investigación científica.

En correspondencia con esta pluralidad, plasmada en los escritos sobre metodología de la investigación, la investigación educativa debe orientarse con la claridad de que los complejos fenómenos sociales y educativos necesitan de una percepción perspicaz y abierta, que haga posible la elección del método o los argumentos teóricos de manera pertinente, en correspondencia con los escenarios sociales donde se desarrollan.

\section{La tradición positivista y la investigación cuantitativa}

El positivismo, que aparece con Augusto Comte, en la primera mitad del siglo XIX, fue la filosofía encargada de respaldar esta actitud teórica nacida del enfoque cartesiano y entre sus contribuciones está la idea del estudio científico de la sociedad humana, a fin de 
superar toda forma especulativa, lo que indica que la realidad social humana debe ser comprendida científicamente.

Esta tradición de pensamiento es un movimiento intelectual heterogéneo, no solo como concepción filosófica, sino también desde sus perspectivas y creencias políticas. Puede ser periodizada en tres etapas fundamentales: el positivismo inicial del siglo XIX, iniciado por Comte, el empiriocriticismo y el neopositivismo o empirismo lógico.

Es importante señalar que desde el enfoque positivista han tenido lugar connotadas aportaciones al conocimiento de la sociedad humana y a la ciencia en general, por lo menos, desde el nivel de demandas al conocimiento, planteadas por las necesidades sociales. Esto, le ha permitido tener un papel protagónico en el desarrollo de la revolución operada en el conocimiento a lo largo del siglo XX.

Con el característico llamado a la exigencia, la precisión, al rigor, al control en la ciencia, establecieron una lucha significativa contra el enfoque metafísico (entendido como razonamiento especulativo), práctica tradicional que viene del pensamiento premoderno, del cual la ciencia debe apartarse según los positivistas. Pero, por otra parte, en ese afán, sentimientos como el amor, el odio, la vergüenza, la alegría pasan a ser estigmatizados por su incapacidad para aportar conocimiento verdadero y deben mantenerse alejados de la actividad científica, al decir de Alfred Ayer "Los juicios de valor (...) en la medida en que no son científicos, no son, literalmente hablando, significativos, sino que son, simples expresiones de emoción que no pueden ser verdaderas ni falsas", (1958, p. 126). Así por el sendero del supuesto rigor científico se llegó a considerar lo valorativo como inservible para la ciencia.

Con este espíritu se configuró la formación de un mito, el mito de la exactitud, cuestionable en todas las áreas de la actividad científica, no solo por la certidumbre y confianza exagerada que produce en los distintos actores sociales, sino también por falta de dialéctica y pertinencia que simboliza. En la investigación educativa esta inconsistencia de la exactitud se acrecienta por tratarse de seres humanos y procesos sociales donde la relatividad del conocimiento es mayor, precisamente porque el aula, el aprendizaje, la docencia, y todos los componentes de los sistemas educativos, forman parte de una idealidad cultural, política y económica insertada en el sistema de relaciones sociales, complejizada aún más por los procesos de internacionalización social acelerados de las últimas décadas. 
A partir de esta visión filosófica de la ciencia, el positivismo asume la falsa idea de neutralidad científica, que excluye la presencia de la subjetividad en la investigación y en sus resultados, calificándola literalmente sin sentido. El siguiente pasaje de Alfred Ayer es ilustrativo de este empeño

Para determinar si una sentencia expresa una hipótesis genuina, adopto lo que puede llamarse un principio de verificación modificado. Porque no exijo por cierto que una hipótesis empírica deba ser verificable en forma concluyente, sino que haya alguna experiencia posible que sea pertinente para la determinación de su verdad o falsedad. Si una presunta proposición no consigue satisfacer este principio, y no es una tautología, entonces sostengo que es metafísica, y que por ser metafísica no es ni verdadera ni falsa, sino literalmente sin sentido. Se hallará que, de acuerdo con este criterio, gran parte de lo que habitualmente se considera como filosofía es metafísica, y en particular que no puede afirmarse en forma significativa que hay un mundo no empírico de valores, o que los hombres tienen almas inmortales, o que hay un Dios trascendente (1967, pp. 17-18).

Es indiscutible que el positivismo ha dejado una huella positiva en el perfeccionamiento de los métodos empíricos y estadísticos, para la búsqueda y procesamiento de la información. Con el objetivo de superar la metafísica se sirvió de las matemáticas para perfeccionar los sistemas estadísticos, los cuales tienen un gran potencial en la identificación de tendencias sociales, estados de opinión o para el diagnóstico de los procesos económicos y políticos de cualquier nación o grupo social. Esto se logra muchas veces con resultados muy fiables en relación con sus predicciones.

Pero en su afán por superar la metafísica en los estudios sociales, y establecer demarcaciones que permitan instituir una distinción entre lo científico y lo no científico, se instauró un reduccionismo que preferencia lo estadístico y la información empírica, en detrimento de la actividad científico teórica; afirmando esta perspectiva con la transferencia de los métodos de las ciencias naturales al estudio de la sociedad, precisamente al escenario en el que habitan la sensibilidad, las emociones, la afectividad y muchos otros sentimientos contenidos en la vida humana y donde estos métodos pueden ser ineficientes.

Por su parte, el positivismo instituyó una visión del método que olvida parte del objeto real de la ciencia, al absolutizar la dimensión cuantitativa, ofrece conocimientos 
parcelados, que no tienen en cuenta que los escenarios sociales y naturales se caracterizan por la multiplicidad de dimensiones y, con ello, impide asumir una comprensión de sistema.

Actualmente, hay gran cantidad de resultados científicos sobre estudios educativos, con enfoque positivista, basados en análisis estadísticos, a partir de encuestas estandarizadas o de aplicación de determinados test, pero cuando se abusa de esta práctica, la información puede no ser adecuada y tiende a descontextualizar los resultados.

El positivismo significó el sostén teórico al establecimiento de la "separación" entre el sujeto investigador y los objetos investigados, al considerar que el mundo, a modo de objeto de investigación, tiene existencia propia independientemente de quien lo estudia. Esta configuración, tal como se afirma en párrafos anteriores, ya estaba plasmada en el pensamiento cartesiano y le da al objeto el papel activo y al sujeto un rol pasivo; una comprensión del sujeto y el objeto como existencias absolutamente diferenciadas y no componentes del proceso de actividad práctica social.

En las investigaciones educativas y en las investigaciones sociales, en general, esta relación de separación entre el sujeto y el objeto impide ver la trama interactiva propia de la educación, pues todos sus componentes conforman estructuras orgánicas muy dinámicas, insertas en una praxis que funde interacciones e ingredientes humanos muy diversos.

Por eso, es necesario asumir una actitud crítica ante la recurrente tendencia de las investigaciones educativas, a encerrar su “objeto"; percepción que enclaustra los sujetos y procesos partícipes de la educación, a espacios incomunicados, como si no fueran protagonistas en la conformación de estructuras objetivo-subjetivas, vinculadas a contextos cada vez más crecientes de procesos de internacionalización de la sociedad.

Todo lo anterior se acompaña de una interpretación mecanicista de la relación causa efecto. A partir de la idea simplista que absolutiza el postulado, según el cual, y de manera mecánica, conociendo las causas podemos actuar sobre los efectos. En realidad, esto ha funcionado muchas veces, pero los efectos pueden ser impredecibles y el esfuerzo investigativo, en sus resultados, ineficaz. En la educación, las estrategias nacidas de la investigación, no siempre en su aplicación, han conducido a resultados felices, precisamente por no tener en cuenta que las relaciones causales actúan en 
espacios muy versátiles y dinámicos. Todo ello llama a la necesidad de reconsiderar las nociones de determinismo, causalidad y pronóstico.

Después de la década de 1960, la corriente de filosofía de la ciencia de orientación positivista entra en crisis, con la propuesta postpositivista de historia de la ciencia como instrumento de exploración filosófica. Sus autores más reconocidos han sido: T. S. Kuhn, I. Lakatos, P. Feyerabend. El giro historicista implicó una comprensión de la ciencia derivada de las interacciones sociales y su estudio se ajustó a los contextos sociológicos y económicos que conformaban su evolución histórica.

Sin embargo, el positivismo en la investigación y en gran parte del discurso político contemporáneo, aún sigue teniendo presencia. Sus alcances teóricos han participado de una sutil combinación junto al pragmatismo y otras teorías, como argumento y contenido de ideales tecnocráticos, prácticas muy sutiles de dominación y de establecimiento de formas hegemónicas corporativas asociadas al capitalismo de corte neoliberal. En consecuencia, una concepción de la sociedad profundamente reaccionaria, encaminada a destruir el pensamiento crítico reflexivo y cultivar la resignación.

Bajo esta influencia en muchos escenarios educativos latinoamericanos se instauró en la década de 1980 un modelo neoconservador que impulsó la "despolitización" en la formación de profesionales, proceso que aún tiene niveles de presencia en las instituciones escolares. Con ello, educar se reduce a formar un "producto" económico para el mercado de trabajo, que elimina al sujeto autoreflexivo y lo condena a admitir el dogma de que este mundo es el mejor de todos los mundos posibles.

Todo ello muy en contradicción con el desempeño de práctica política que, en general, asumieron muchos de los pensadores positivistas, de defensa de la paz y de promoción de ideales de justicia social e igualdad.

En resumen, se puede afirmar que la influencia dejada por la tradición positivista en investigación educativa limita la contribución que las escuelas y universidades pueden hacer a la generación de nuevos conocimientos; para mejorar los procesos sustantivos que desarrolla, en aras de una educación más humanista y científica, más integral e inclusiva, que responda mejor a las necesidades sociales e individuales actuales y a un modelo de mundo más justo, equitativo y sostenible. Sin embargo, el positivismo dejó una distinción de rigor y de espíritu de búsqueda que constituyen valores indispensables en la actividad científica. 


\section{La dialéctica materialista como enfoque filosófico para la investigación científica}

La dialéctica materialista se desarrolla de forma paralela y alternativa al enfoque filosófico positivista, al incluir en la investigación un giro social de interpretación de la actividad científica. Aunque tiene arraigos profundos en la tradición evolutiva del pensamiento humano, la teoría generalmente se identifica con la labor de Carlos Marx y Federico Engels.

El marxismo surgió en Europa a mediados del siglo XIX. Una corriente de pensamiento que no se mantuvo como un bloque monolítico, más bien, se bifurcó en tendencias, corrientes, escuelas y autores; en definitiva, una expresión de una diversidad bastante copiosa de creencias.

Por razones de influencia política y por su activismo académico en la producción de manuales de filosofía y de metodología de la investigación, es el marxismo soviético, la corriente que se desarrolló en la antigua URSS a lo largo del siglo XX, la tradición que dentro del marxismo dejó mayor influencia en la investigación social.

Independientemente de algunas proyecciones internacionales hacia la paz, la igualdad y los derechos sociales, el marxismo-leninismo de orientación stalinista estuvo revestido de muchas creencias dogmáticas, de rigidez doctrinaria e intolerancia, que generaron influencias negativas en la investigación. También, el marxismo-leninismo asume el enfoque positivista en el uso del método científico y en la producción de conocimientos, en especial la dicotomía cartesiana del sujeto y el objeto, su noción de objetividad y la sobrevaloración del papel en la ciencia de los métodos cuantitativos.

En realidad, la visión positivista asumida por la tradición del marxismo leninismo de orientación soviética difiere en numerosos puntos de las concepciones expuestas por Carlos Marx. Como se puede apreciar, en el siguiente fragmento, extraído de las Tesis sobre Feuerbach,

El defecto fundamental de todo el materialismo anterior -incluido el de Feuerbaches que sólo concibe las cosas, la realidad, la sensoriedad, bajo la forma de objeto o de contemplación, pero no como actividad sensorial humana, no como práctica, no de un modo subjetivo, (1981, p. 2)

para Marx la sensoriedad, la materialidad se concibe como práctica, a modo de actividad subjetiva, donde "lo ideal no es más que lo material, transpuesto e interpretado 
en la cabeza del hombre", (1962, p. 8). Estos fragmentos son indicativos de que Marx reconoce el papel de la subjetividad en los seres humanos, fruto constitutivo del sistema de relaciones sociales y de la práctica.

Es evidente que en el pensamiento de Marx existe una clave interpretativa radicalmente diferente de la noción de objetividad, contenida en el positivismo y el marxismo de la tradición soviético stalinista, lo cual se expresa en el entendimiento de que el conocimiento ocurre en una relación práctica, mediada social y culturalmente y que, por lo tanto, el saber y la objetividad tienen espacios y fronteras culturales objetivo-subjetivas (Delgado, 2001).

Sin embargo, a pesar de que las bases epistemológicas planteadas por Marx abren el camino para entender lo cualitativo, la tradición marxista inicial no desarrolló los instrumentos teóricos y metodológicos necesarios para la investigación que permitieran interpretarlo, este fue el aporte de la fenomenología y posteriormente de otras corrientes, entre las que se encuentra la llamada la Teoría Crítica, desarrollada en la Escuela de Francfort, de influencia marxista.

Los autores del presente ensayo, a partir de reconocer que muchas de las creencias epistemológicas del enfoque dialéctico materialista en la interpretación del conocimiento, del método científico y la ciencia no son privativos del marxismo, pues se pueden encontrar contenidos en otras concepciones teóricas y con la consideración de que la dialéctica deja de ser dialéctica desde el momento en que se trata de parcelar sus componentes, presentan algunos de sus elementos constituyentes, así como argumentos de significado para la investigación educativa:

- El universo al que se incorpora nuestro planeta es dinámico y evoluciona en un devenir matizado por una afluencia diversa de cambios, contradicciones, y de una red infinita de interacciones y relaciones. Esta idea parte de un enfoque de la realidad de gran importancia para la investigación educativa; la educación es partícipe de un escenario cambiante, acrecentado en las últimas décadas por la incursión de la tecnología digital en sus procesos; cada grupo de estudiantes, las materias que se aprenden, los claustros docentes, el sistema educativo, la evaluación, el sistema de leyes que la instituyen, la sociedad en que se inserte; todo participa de una dinámica propia, que se integra a sistemas más complejos y globales. 
- Por su parte, esa dinámica, esa dialéctica de la educación, cobra mayor interés por los retos que la sociedad contemporánea plantea, asociados a: el desarrollo de nuevas tecnologías, el deterioro del medio, el tratamiento a la cuestión del género, la democratización y la disparidad económica y cultural, etc.

- La concepción materialista de la historia es el eje de la dialéctica materialista, principal aportación del pensamiento marxista, expuesta en múltiples obras como la Ideología Alemana, El Capital, El Manifiesto Comunista, etc. Esta concepción no significa un burdo economicismo determinista para el cual solo los factores económicos son los únicos socialmente determinantes; el mismo Engels se encargó, en carta a José Block, de aclarar su puntos de vista al expresar

La situación económica es la base, pero los distintos factores de la superestructura que sobre ella se levanta (...) ejercen también su influencia sobre el curso de las luchas históricas y determinan predominantemente en muchos casos su forma. Es un juego mutuo de acción y reacción. (1980, p. 275)

- Es importante destacar que aunque la concepción materialista de la historia es un importante instrumento para comprender muchos de los procesos que acontecen en la sociedad y en la educación, pero, como se señala en párrafos anteriores, esta no puede ser considerada como la única clave explicativa de todo, es un enfoque útil, indispensable para el entendimiento, pero no agota la realidad.

- Sin embargo, en la investigación educativa, este enfoque permite entender los procesos educacionales en sus componentes materiales y espirituales insertos en el sistema de relaciones sociales, ver la educación como segmento, no demarcado del resto de las actividades sociales, de la base económica y de la superestructura social y evaluar en ella la diversidad de influencias ideológicas participantes, así como el marco institucional en que tiene lugar.

- Presente también en otras corrientes de pensamiento, de análisis histórico concreto o historicismo, como dimensión del devenir de la naturaleza y la sociedad humana: los valores, el conocimiento, la civilización, la cultura, las formas productivas, etc., el enfoque concurre en una temporalidad y en una ubicación espacial. Desde esta perspectiva se entiende que la sociedad es un organismo vivo, que se autoconstruye y autodestruye continuamente en el espacio y en el tiempo.

- La historia tiene un peso en la educación, es el depósito de la experiencia de millones de maestros y alumnos, de instituciones educativas, en ella se recogen las 
creencias muchas veces ancladas en aportaciones del pensamiento pedagógico. Experiencias y tradiciones vinculadas con la historia política y económica de la humanidad y de las distintas regiones y pueblos; la humanidad es fruto de ese incesante proceso evolutivo. Si en la investigación hay una toma de conciencia del peso de lo histórico, entonces en ella hay dialéctica.

- La dialéctica materialista considera que el movimiento es ininterrumpido y que transcurre como proceso a través de diversas direcciones en una unidad de cambios progresivos y bruscos, de continuidad y ruptura, por lo que lo cuantitativo y lo cualitativo son considerados, no a modo de pares separados, sino de unidad dialéctica que se expresa en el contexto, en la relación concreta que los activa. Lo cuantitativo y lo cualitativo en Marx se combinan en la búsqueda del conocimiento a través del proceso de actividad práctica.

- De esta interpretación se deriva que en la investigación social y educativa es el contexto, la pertinencia, los fines, lo que se desea saber, las características de los sujetos participantes de la investigación, ya sea como sujetos investigados o sujetos investigadores, quien determina la metodología elegida; lo cuantitativo y lo cualitativo coexisten en una dinámica que los integra. Por lo tanto, de la interpretación que se hace de estos escenarios dependen las características de los métodos y técnicas a elegir. La dialéctica materialista no niega la investigación cualitativa.

- La dialéctica materialista tiene fines sociales emancipatorios asociados a la superación de la pobreza, la exclusión, las grandes desigualdades y comprende la educación como uno de los caminos para hacer posible esos fines, lo que significa entender que la educación y la investigación están al servicio de la justicia, del humanismo, la igualdad, del reconocimiento a la diversidad social y natural, del enfoque de género, de la distribución y gestión democrática del conocimiento. Para la dialéctica materialista la educación tiene la misión de humanizar.

- De lo anterior se desprende el reconocimiento de que la ciencia, la investigación científica y la educación son procesos axiológicos valorativos, que se plasman en fines, demandas, necesidades sociales e intereses, se entiende que siempre hay consideraciones filosóficas, éticas y políticas insertas en las teorías y en los sistemas educativos, destacando la presencia de intereses de clase, grupos y 
naciones en la investigación. En esencia, es lo opuesto a la idea de la neutralidad científica defendida por el positivismo

- Esto implica reconocer que, desde una perspectiva contraria a la anterior, los proyectos de investigación educativa pueden ser usados como herramientas para justificar formas hegemónicas de dominación, ligadas al colonialismo y al capital transnacional, por lo que también pueden ser usados para deshumanizar. En este sentido, la dialéctica materialista es un arma para la crítica a esta tendencia.

- El enfoque dialéctico, al considerar la sociedad como parte de la evolución de la naturaleza, apunta también a reconocer que son accesibles al conocimiento, es decir, cognoscibles en la interacción, aproximación, coincidencia sujeto objeto, elementos estos, que se construyen y reconstruyen de manera histórica. Por lo tanto, la acción de conocer no es un resultado estático, lineal, siempre medible, sino que es un proceso activo y dinámico. Lenin expresó esta idea al afirmar que "El conocimiento humano no es (no sigue) una línea recta, sino una curva que se aproxima infinitamente a una serie de círculos, a una espiral" (1979, p. 355). Esa dialéctica del conocimiento identifica la presencia de la unidad de lo empírico y lo teórico y la existencia de la verdad como proceso en sus dimensiones relativoabsolutas.

- El pensamiento dialéctico integra, en el proceso de investigación, el tránsito de lo abstracto a lo concreto, el análisis y la síntesis, lo histórico y lo lógico, no como dicotomías absolutas, sino como aspectos del universo del pensamiento, transiciones de uno en otro, complementariedad, flujos y reflujos que se realizan en la práctica que conecta al sujeto y al objeto.

- Dialéctica materialista es espíritu de crítica, en cualquier texto de Carlos Marx la crítica es un componente esencial para el mejoramiento humano. Para la dialéctica materialista en la ciencia no hay nada sagrado, todo puede ser cuestionado y las aspiraciones a la verdad se legitiman con pruebas y argumentos, nada queda excluido de esta dialéctica.

- En la investigación educativa la crítica juega un papel diverso: orientadora, permite rectificar, posee un potencial educativo excepcional, participa de la construcción de la cultura científica. 
Los componentes expuestos del enfoque dialéctico materialista obedecen a una lógica de sentido metodológico, cuya vigencia es indiscutible, pero lo importante en la investigación educativa es descubrir la dialéctica contenida en la red de conexiones de los sujetos sociales que investigan o son investigados, es decir, del sistema de contradicciones que se conforman en los distintos procesos de la educación. Solo con ello se logra la autoformación de un pensamiento dialéctico interpretativo en los investigadores y en los distintos individuos que participan del sistema educativo.

La dialéctica materialista del marxismo, en su contenido, incorporó ideales libertarios. Es precisamente, la educación uno de los campos donde se fundan acciones y conciencias para tal empeño. El concepto de libertad en su contenido participa de esa dinámica dialéctica indetenible y crea nuevas relaciones de significado con sus términos para designarlas. La educación ha reflejado esos cambios con nuevos conceptos como educación multicultural, calidad, pertinencia, cultura de paz, competencias, etc., terminologías que matizan los problemas científicos que empeñan a gran parte de la investigación educativa actual y que manifiestan el momento histórico en que se vive. Pero en este terreno, de interpretación del fenómeno educativo, la tradición marxista, desde la década de 1960, no ha estado al orden del día, al no generar desarrollos teóricos que le permitan reproducir los acontecimientos.

\section{La fenomenología y la investigación cualitativa}

La fenomenología ocupa un espacio importante en el panorama filosófico de buena parte del siglo XX. Aparece en estrecha conexión con el positivismo y la dialéctica materialista del marxismo. Es un proyecto de pensamiento con dimensiones filosóficas, políticas y de aportación a la metodología científica, que capta el rechazo al cientificismo positivista y el vacío de investigaciones sobre la subjetividad humana, presente en la tradición marxista, que, en principio, aunque reconoció su existencia, no fue más allá de valorar su importancia política para los fines de transformación social.

En el desarrollo de la fenomenología también hay que tener en cuenta la reacción antipositivista que se desarrolla a finales del siglo XIX y principios del XX, tradición que incluye diversos autores que, en general, pusieron en duda la posibilidad de la conquista de la verdad por parte del hombre, utilizando el método científico y que con ello se pueda contribuir al deseado proceso de liberación humana. Destacan autores que tradicionalmente son agrupados con el término irracionalismo, S. Kierkegaard, A 
Schopenhauer, J. Maritain, F. Nietzsche, quienes centraron su atención en aquellos temas ligados a la subjetividad interior de los hombres, que por su naturaleza eran muy difíciles de cuantificar. Estos autores encontraron en los intelectuales de la cultura artística su base social y pusieron en duda el papel de la ciencia.

La fenomenología utilizó la ciencia para estudiar aquellos fenómenos o componentes de la espiritualidad, no investigados por la tradición marxista, negados como objeto de valor para la ciencia, por el positivismo y usados como argumento de descalificación de la ciencia por el irracionalismo.

En sus orígenes asume como base epistemológica la filosofía de Edmund Husserl (1859-1938), pero se constituyó en un importante movimiento de posiciones muy heterogenias, con autores como Max Scheler y Martin Heidegger y, a la vez, recibió la influencia del pragmatismo norteamericano de John Dewey.

Se trata de fundar una ciencia rigurosa de las esencias de ciertas estructuras conscientes y particulares. Esas estructuras se relacionan con una interpretación de los sentimientos: la angustia, el amor, los estados de ánimo, el asombro, la duda, el espanto, el éxtasis; en el fondo, una especie de experiencia pura que se define como el objeto propio de la fenomenología. Con ello, el ser queda reducido a la conciencia y al ser que se da a conocer en la conciencia. "Por lo que toca a la fenomenología, quiere ser una ciencia descriptiva de las esencias de las vivencias puras trascendentales en actitud fenomenológica" (Husserl, 1949, p. 166).

El método fenomenológico exige alejarse de toda idea previa, teoría, modelo o tesis interpretativa, a fin de evitar caer en prejuicios. Es la investigación de lo que se da en la conciencia, con exclusión de postulados precedentes o tesis interpretativas ya establecidas; así como de todo supuesto o convicción sobre la existencia o no existencia de aquello que se da. Es atenerse a aprehender lo que se da a la conciencia y no apelar a modelos, fórmulas y convicciones previas, para no incurrir en parcialidades y en los conceptos obstáculos que puedan desviar la conciencia de su ruta hacia la verdad.

Desde esta perspectiva epistemológica se desarrolla lo que se conoce como paradigma de investigación cualitativa, actualmente muy usado en la investigación social y, en especial, en la investigación educativa. Con ello surgieron instrumentos muy útiles para comprender las estructuras latentes de la espiritualidad humana, que permitieron indagar allí donde la metodología tradicional, de corte positivista, no funciona. 
La historia de vida, la entrevista en profundidad, la observación participante, y otros métodos y procedimientos cualitativos se han ganado un lugar en la investigación.

El enfoque fenomenológico desde sus aportaciones se ha convertido en un instrumento indispensable para la búsqueda de información en los escenarios educativos y para la conformación de estrategias para mejorar el desempeño docente, muy atractivas en la investigación, pues el aula es un espacio donde convergen relaciones intersubjetivas bien diversas.

El lado débil de la fenomenología consiste en que desde esta filosofía se establece una jerarquización desmedida de la subjetividad social humana, que margina el objeto y conduce al subjetivismo, al negar la objetividad de las relaciones sociales y a cualquier reconocimiento de fenómenos materiales más allá de la conciencia humana. Esto hace de su propuesta filosófica una teoría que repite el subjetivismo tradicional, al afirmar que solo la conciencia tiene una existencia real y que el mundo material, el ser, la naturaleza, solo existe en nuestra conciencia, en nuestras sensaciones, en nuestras percepciones, en nuestros conceptos.

Es por eso que asumir la metodología cualitativa, desde los escenarios latinoamericanos, implica la necesidad de cierta cautela epistemológica, porque detrás del idealismo contenido en sus propuestas, existen manipulaciones ideológicas intencionadas. Al excluir la dinámica del objeto se reducen los problemas sociales a lo intersubjetivo, con lo cual se excluye la necesidad de la transformación de la realidad como misión básica de la ciencia que la estudia, lo que, al mismo tiempo, significa un rechazo al papel de la educación en la formación de ideales políticos comprometidos con el cambio social. Por su parte, esta postura también refuerza un espíritu que absolutiza lo individual en detrimento de la acción colectiva.

Estas creencias, que de hecho son formas sutiles de hacer política y fabricar ideologías de dominación, nada tienen que ver con el imperativo de formación de sujetos políticos implicados con los destinos libertarios, tan significativos para la región.

\section{Síntesis y reflexiones finales}

Raras veces un enfoque filosófico brinda, de manera acabada, los argumentos explicativos necesarios para interpretar la actividad científica y, en especial, la concepción del método, sobre todo, si se considera la complejidad de los eventos sociales y en particular la complejidad de la educación, donde la presencia de lo inesperado y lo 
inexplicable es lo cotidiano. Es por ello recomendable asumir una concepción electiva, que permita conformar marcos interpretativos que se correspondan con las realidades educativas investigadas.

Aunque el positivismo, la dialéctica materialista y la fenomenología han tenido una marcada influencia en la investigación social, razón por la cual han ocupado el espacio de este ensayo, en la actualidad, se han desarrollado toda una serie de teorías que aportan novedosos enfoques del método científico, cuyas contribuciones no son nada despreciables y, en muchas casos, representan construcciones teóricas que deben ser escuchadas y tenidas en cuenta: los trabajos de M. Foucault, aparecidos bajo el título de Microfísica del poder, las teorías deconstrucciones del logocentrismo de Derrida, la Teoría de la Complejidad de E. Morin, el holismo ambientalista, la epistemología de segundo orden, la bioética, el concepto del buen vivir asociado a los pueblos originarios, etc., son algunos ejemplos que matizan el pensamiento presente, que contienen lógicas de razonamiento que pueden servir de argumento para justificar las investigaciones e interpretar los resultados.

Para Latinoamérica, donde todo adquiere los matices del subdesarrollo, asumir un enfoque filosófico de pensamiento autóctono es condición indispensable para garantizar una contribución, realista y efectiva al permanente proceso de liberación humana, función ineludible de los sistemas educativos y de la ciencia que debe realizarse. El pensamiento propio, desarrollado desde la realidad regional, puede y debe tener espacios de elección en otras tradiciones, pero desde una cautela epistémica que le permita deshacerse de mensajes de dominación cultural.

Finalmente, las investigaciones educativas no deben reducirse al enfoque filosófico del método, pues la ciencia contiene componentes éticos, políticos, ambientales y económicos indispensables para justificar su pertinencia. Por lo que problemas como el de la identidad latinoamericana o nacional, la soberanía y la independencia, la responsabilidad social, la gestión democrática, el respeto a la diversidad, la lucha contra la pobreza, entre otros temas, entran a formar parte y repercuten en la actividad científica y en los criterios de elección y fundamentación del método científico. Este es el punto de vista que permite una percepción de sistema en la investigación educativa, al mismo tiempo, es una condición para garantizar la funcionalidad, efectividad y el sentido a los resultados. 


\section{Referencias}

Ayer, Alfred Jules. (1958). On the Analysis of Moral Judgments. En Milton Munitz (ed.), Modern Introduction to Ethics (Capítulo Crítica de la ética y la teología). Nueva York: Free Press.

Ayer, Alfred Jules. (1967). El positivismo lógico. La Habana: Instituto del libro

Bunge, Mario. (2002). Ser, saber, hacer. México: Piadós.

Delgado, Carlos. (2001). Los Límites socioculturales de la educación ambiental. La Habana: Siglo XXI.

Delgado, Carlos. (2002). La racionalidad no clásica y sus perspectivas metodológicas. En Thalía Fung y Juan de Dios Pineda (eds.), Los desafíos de la ciencia política en el siglo XXI. La Habana, Cuba: Universidad de la Habana.

Descartes, René. (1984). Reglas para la dirección del espíritu. Madrid: Alianza.

Descartes, René. (1953): Discurso del método. Barcelona: Editorial Fama.

Engels, Federico. (1980). Carta de Engels a José Block en Königsberg. Londres 21-22 de septiembre de 1890. Obras Escogidas en tres tomos de Marx y Engels, Tomo III. Editorial Progreso Moscú.

Heidegger, Martin. (1975). La pregunta por la cosa. Buenos Aires, Argentina: Alfa.

Husserl, Edmund. (1949). Ideas relativas a una fenomenología pura y una filosofía fenomenológica. México: FCE.

Lenin, Vladimir llitch. (1979). Cuadernos filosóficos. La Habana, Cuba: Editora política.

Marx, Carlos. (1962). Postfacio a la segunda edición del Tomo I del Capital. La Habana, Cuba: Editorial Ciencias Sociales.

Marx, Carlos. (1981). Tesis sobre Feuerbach. En Obras escogidas (Tomo I). Moscú: Editorial Progreso.

Morin, Edgar, Ciurana, Roger y Motta, Raúl Domingo. (2002). Educar en la era planetaria. El pensamiento complejo como Método de aprendizaje en el error y la incertidumbre humana. Valladolid, España: Universidad de Valladolid, Secretariado de Publicaciones e Intercambio Cultural.

Morin, Edgar. (1999). Los siete saberes necesarios para la educación del futuro. Paris, Francia: Organización de las Naciones Unidas para la Educación, la Ciencia y la Cultura. 